\title{
Ferramenta Interativa para a Promoção da Humanização na Atenção Às Pessoas que Convivem com a Doença Falciforme
}

\author{
Valêncio, Luis Felipe Siqueira; Oliveira, Renan Garcia de; Barberino, Willian Marcel; \\ Guimarães, Felipe Dorigão; Costa, Carolina Frandsen P. da; Domingos, Claudia \\ Regina Bonini \\ Instituto de Biociências, Letras e Ciências Exatas (Ibilce/Unesp) - \\ luisfelipevalencio.unesp@gmail.com
}

\begin{abstract}
INTRODUÇÃO a doença falciforme (DF) é uma anemia hereditária, caracterizada pela produção de uma hemoglobina anormal, denominada hemoglobina $(\mathrm{Hb}) \mathrm{S}$. em algumas condições específicas, essas hemoglobinas se polimerizam no interior do eritrócito, resultando na formação de células falciformes, menos flexíveis. Essas células aderem aos vasos sanguíneos e são propensas à hemólise. Devido à sua origem no continente africano e, consequentemente, à constituição étnica da população brasileira, a DF tem alta frequência no Brasil, sendo que em alguns estados, a $\mathrm{Hb}$ S está presente em 1 a cada 17 indivíduos na população. a vulnerabilidade das pessoas que vivem com doença falciforme pode apresentar-se em três diferentes aspectos: biológico, social e cultural, relacionados à gravidade e complicações decorrentes da doença; ao racismo institucional e interpessoal, podendo conferir menores índices de escolaridade e desenvolvimento humano; à subjugação das tradições, costumes e religiosidade de matriz africana. OBJETIVOS Criar uma ferramenta que una todos os sujeitos envolvidos com essa temática, como agentes da saúde, pessoas com DF e pesquisadores, a fim de diminuir as distâncias no diálogo entre esses 3 componentes. Pretendemos e permitir um ambiente de discussão em que todas essas vozes tenham força e, juntas, busquem melhorias no tratamento e atenção a DF. MÉTODOS o projeto baseia-se em elementos da bioética de proteção como: redução da vulnerabilidade e resgate da autonomia das pessoas que vivem com a DF, favorecendo a promoção do autocuidado. para isso, estão sendo elaborados vídeos, no formato de entrevistas, organizados em pequenos capítulos para facilitar o acesso. Contribuem para o proposto, pessoas com DF (a explicação do projeto e aceitação em participar foi obtida de forma coletiva durante a reunião de uma associação de pacientes, no VII Simpósio Brasileiro de Doença Falciforme); profissionais da atenção básica e pesquisadores, integrando os diferentes saberes. Acredita-se que será gerado material para complementar a informação já transmitida pelo SUS. Posteriormente, os vídeos serão disponibilizados gratuitamente na plataforma YouTube. RESULTADOS Apesar de estar em processo de elaboração, os resultados preliminares são positivos. a maior proximidade entre os pesquisadores envolvidos e as pessoas com doença falciforme é motivadora e confere um aprendizado antes inacessível. Reforça a participação do pesquisador no construir da saúde, e populariza o conhecimento científico, muitas vezes aprisionado aos periódicos científicos. CONCLUSÕES a necessidade de aumentar a vivência dos pesquisadores com os momentos de reflexão do fazer científico na saúde e o fortalecimento do contato com as pessoas que convivem com a doença falciforme contribuem para a construção coletiva de uma saúde melhor.
\end{abstract}

Valêncio, Luis Felipe Siqueira; Oliveira, Renan Garcia de; Barberino, Willian Marcel; Guimarães, Felipe Dorigão; Costa, Carolina Frandsen P. da; Domingos, Claudia Regina Bonini. Ferramenta Interativa para a Promoção da Humanização na Atenção Às Pessoas que Convivem com a Doença Falciforme. In: Anais do Congresso Internacional de Humanidades \& Humanização em Saúde [= Blucher Medical Proceedings, num.2, vol.1]. São Paulo: Editora Blucher, 2014. ISSN 2357-7282

DOI 10.5151/medpro-cihhs-10301 